\title{
Dialysis-associated peritonitis in children
}

\author{
Vimal Chadha $\cdot$ Franz S. Schaefer $\cdot$ Bradley A. Warady
}

Received: 15 August 2008 /Revised: 18 November 2008 / Accepted: 9 December 2008 /Published online: 4 February 2009

(C) IPNA 2009

\begin{abstract}
Peritonitis remains a frequent complication of peritoneal dialysis in children and is the most common reason for technique failure. The microbiology is characterized by a predominance of Gram-positive organisms, with fungi responsible for less than $5 \%$ of episodes. Data collected by the International Pediatric Peritonitis Registry have revealed a worldwide variation in the bacterial etiology of peritonitis, as well as in the rate of culturenegative peritonitis. Risk factors for infection include young age, the absence of prophylactic antibiotics at catheter placement, spiking of dialysis bags, and the presence of a catheter exit-site or tunnel infection. Clinical symptoms at presentation are somewhat organism specific and can be objectively assessed with a Disease Severity Score. Whereas recommendations for empiric antibiotic
\end{abstract}

V. Chadha

Department of Pediatrics, Section of Nephrology, Virginia

Commonwealth University Medical Center,

Richmond, VA, USA

F. S. Schaefer

Center for Pediatric and Adolescent Medicine,

Section of Pediatric Nephrology, University of Heidelberg,

Heidelberg, Germany

B. A. Warady

Department of Pediatrics, Section of Nephrology,

The Children's Mercy Hospital,

Kansas City, MO, USA

B. A. Warady $(\bowtie)$

University of Missouri-Kansas City School of Medicine,

The Children's Mercy Hospital,

2401 Gillham Road,

Kansas City, MO 64108, USA

e-mail: bwarady@cmh.edu therapy in children have been published by the International Society of Peritoneal Dialysis, epidemiologic data and antibiotic susceptibility data suggest that it may be desirable to take the patient- and center-specific history of microorganisms and their sensitivity patterns into account when prescribing initial therapy. The vast majority of patients are treated successfully and continue peritoneal dialysis, with the poorest outcome noted in patients with peritonitis secondary to Gram-negative organisms or fungi and in those with a relapsing infection.

Keywords Antibiotics · Children · Infection · Peritonitis · Peritoneal dialysis

\section{Introduction}

Chronic peritoneal dialysis (CPD) remains the most common dialysis modality utilized for the management of children with end-stage renal disease (ESRD), and its usage is expanding in many developing countries [1-3]. Despite the decreasing incidence of CPD-related infectious complications in both children and adults over the past two decades, peritonitis remains the most significant complication of CPD in the pediatric population $[4,5]$. Peritonitis contributes to significant morbidity and can lead to irreversible technique failure. Records from the United States Renal Data System (USRDS) reveal that infectious complications are the most frequent cause for hospitalization among children receiving CPD and that the cumulative incidence of hospitalization over a 36-month period increased from $19.3 \%$ in the period $1995-1998$ to $34.3 \%$ in the period 1999-2002 [6]. Furthermore, according to the data from the North American Pediatric Renal Trials and Collaborative Studies (NAPRTCS), peritonitis is the 
primary reason for modality change in children receiving CPD [2]. These facts mandate an effective approach to the prevention and treatment of CPD-related infections in children who face a lifetime of ESRD care.

To optimize the efficacy of antibiotic therapy, minimize patient morbidity, and hopefully preserve the function of the peritoneal membrane of patients prescribed CPD, the International Society of Peritoneal Dialysis (ISPD) published its first set of peritonitis treatment guidelines in 1983, and updated versions of these guidelines were published in 1989, 1993, 1996, 2000 and, most recently, in 2005 [7-10]. However, with recognition of the presence of risk factors and clinical features unique to children, an international committee published largely opinion-based pediatricspecific guidelines in 2000 [11]. Information derived from the larger adult experience that was also applicable to children was incorporated into the recommendations.

Subsequently, in order to assess the efficacy and validity of these guidelines and to enhance existing knowledge regarding the global bacteriology and antibiotic susceptibility associated with peritonitis in children, the International Pediatric Peritonitis Registry (IPPR) was established and collected/published data from a consortium of 44 pediatric dialysis centers in Europe, Turkey, Asia, and America [12-15]. While the initial pediatric-specific guidelines published in 2000 form the backbone of this review, the new information from the IPPR is incorporated in pertinent sections.

\section{Incidence of peritonitis}

Over the past several decades, there has been a steady decline in the rate of peritonitis in both children and adults that is largely due to improvements in connection technology and a decreased incidence of touch contamination [16-19]. While the rate of infection in adults has fallen to 0.5 episodes per patient-year (one infection every 24 months) in many centers, and rates as low as $0.23-$ 0.29 episodes per patient-year have been reported [20, 21], the frequency of peritonitis in children regularly exceeds that in adults. In the most recent annual report of the NAPRTCS, which includes data collected through January 2007, there were 3892 episodes of peritonitis in 5764 years of follow-up for an annualized rate of 0.68 (one episode every 17.8 months) [2]. This rate has significantly improved in comparison to the annualized rate of 0.91 that was reported in the 1997 NAPRTCS data [22]. Similar to previous reports, the current NAPRTCS report reveals an inverse relationship between the age of the patient and peritonitis rate, with the youngest patients $(<1$ year) having an annualized rate of 0.86 (one infection every 13.9 months), while the adolescents ( $>12$ years) have a rate of 0.61 (one infection every 19.8 months). These rates were derived from clinical experience in the USA and are comparable to what has been documented in European centers, but poorer than the exceptionally low rates (one infection every 28.6 months) found among Japanese children [23-25].

Population-based peritonitis rates, however, can be misleading because of an uneven distribution of individual peritonitis rates. For example, only 38.8 and $52.4 \%$ of patients in the NAPRTCS database had at least one episode of peritonitis within 12 and 24 months of dialysis initiation, respectively, and in those patients who experienced an infection, the frequency varied from only one infection in 788 patients to more than eight infections in each of 48 patients [2]. This type of data emphasizes the potential value of the determination of subject-specific peritonitis incidence data [26].

The frequency of peritonitis is also affected by the type of PD modality, with somewhat better rates for patients who receive automated peritoneal dialysis (APD) versus those that receive continuous ambulatory peritoneal dialysis (CAPD). In the latest NAPRTCS annual data report, the median time to the first peritonitis episode was shorter in CAPD than APD patients; at 1 year post-dialysis initiation, $45.5 \%$ of CAPD patients experienced peritonitis compared to $40.6 \%$ of APD patients [2]. Finally, patients on nocturnal intermittent PD (cycler at night with a dry day) may have a decreased risk of infection compared to those with a wet day because the empty abdomen can enhance local immune function [27].

\section{Microbiology of peritonitis}

Similar to adults, the majority of peritonitis episodes in children on CPD are caused by bacteria, with fungi being responsible for $<5 \%$ of the episodes [28]. Historically, 50 $60 \%$ of the peritonitis episodes have been caused by Grampositive bacteria and $20-30 \%$ by Gram-negative organisms, with cultures remaining negative in a substantial percentage $(<20 \%)$ of peritonitis episodes. Due to a steady decline in the peritonitis rate over the last few decades, likely as a result of improvements in connection technology and exitsite care and in the prophylaxis for Staphylococcus aureus nasal carriage, the distributive pattern of microorganisms has changed and is currently reflected by a selective decrease in the incidence of Gram-positive peritonitis, leaving Gram-negative peritonitis as an increasingly important infectious complication [21, 29, 30]. This pattern, apart from minor disparities, had been believed to be fairly consistent across different dialysis centers caring for children and adults until a recent analysis of IPPR data revealed a significant worldwide variation in dialysisassociated peritonitis characteristics in children [13]. 
Between October 2001 and December 2004, the IPPR gathered data on 501 episodes of peritonitis that occurred in 392 children. Only ten (2\%) of these episodes were caused by fungi. Of the remaining 491 episodes, $44 \%$ were caused by Gram-positive organisms and $25 \%$ by Gram-negative organisms; the culture remained negative in $31 \%$ of episodes. While the results confirmed the earlier impression of a decrease in the rate of Gram-positive infections, the bacteriological profile of the Gram-positive organisms was somewhat different from that recently reported in a survey of $>4000$ episodes of peritonitis in adult patients from the USA and Canada [31]. In contrast to the results of the adult survey in which coagulase-negative staphylococci were threefold more common than $S$. aureus as a cause of peritonitis, staphylococcal organisms were nearly evenly divided among the above two groups in the data gathered by the IPPR (Fig. 1). Furthermore, there was significant variation in the distribution of organisms between different global regions (Fig. 2). Gram-positive infections were predominant in Europe, with coagulase-negative staphylococci being most common in Eastern Europe, S. aureus predominating in Western Europe, and Enterococcus species being most prevalent in Turkey [13].

Worldwide variation was found among Gram-negative organisms. Whereas Gram-negative organisms accounted for $70 \%$ of culture-positive infections in Argentina, they accounted for $46 \%$ of infections in the USA and for only $25 \%$ of infections in European countries. While Pseudomonas was the predominant Gram-negative organism in the USA, other Gram-negative organisms were more common in Argentina [13]. The reason for this marked geographical variation in the bacterial spectrum is most likely multifactorial and may include environmental influences (climate and humidity) and various aspects of PD practices, such as exit-site care and the routine use of topical antibiotic prophylaxis (vide infra) [3].

Not only did the bacteriological profile differ from region to region in the IPPR data, but there was also a striking regional variation in the rate of culture-negative peritonitis episodes. In Turkey and Mexico, effluent cultures remained sterile in $42 \%$ and $67 \%$ of cases, respectively in contrast to a sterile culture rate of $11-23 \%$ in the other regions surveyed [13]. A survey of the laboratory procedures practiced in the individual centers did not reveal any systematic differences in culture technique that would explain these marked differences, but this aspect is currently being evaluated further. It is possible that other issues, such as incubation of insufficient effluent volumes, long transport times in rural areas, and extreme ambient temperatures, may have adversely affected the ability to obtain positive culture results. At the turn of the century, a number of culture-negative peritonitis episodes were reported that were associated with the usage of icodextrin solution for PD [32-34]. Subsequent investigations revealed that these cases of sterile peritonitis were caused by a peptidoglycan (released from Alicyclobacillus acidocaldarius, a Gram-positive organism) contaminating the cornstarch used for icodextrin production [35]. The problem has since been resolved following implementation of a routine serial monitoring program of icodextrin solutions for peptidoglycan during the manufacturing process. A recently concluded multicenter, longitudinal, prospective cohort study that included 722 PD patients did not find any difference in the rates of either infectious or culture-negative peritonitis associated with the usage of icodextrin [36].

As already mentioned, fungi account for only a minority of peritonitis episodes and represent just $2 \%$ of episodes in
Fig. 1 Distribution of causative organisms among 501 episodes of peritonitis reported by the International Pediatric Peritonitis Registry (IPPR) (with permission from [14]). MRSA Methicillin-resistant Staphylococcus aureus, coag. Neg. Staph coagulase-negative staphylococcus

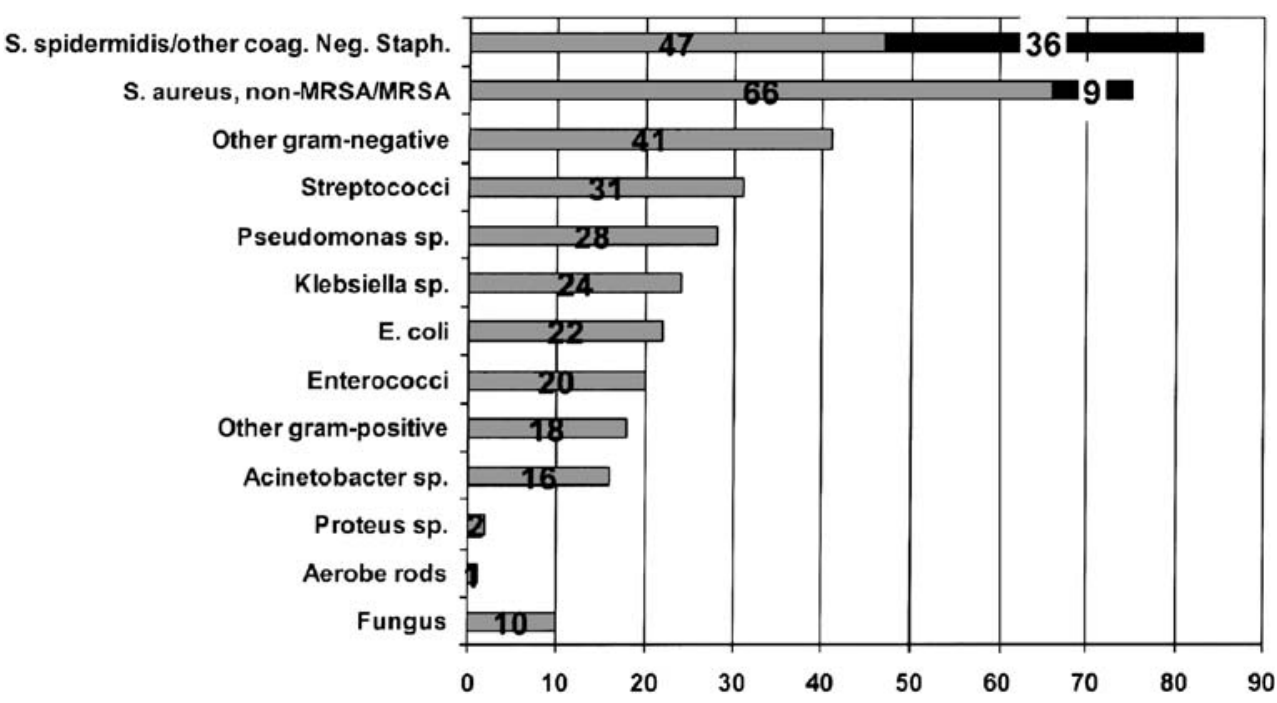


Fig. 2 Distribution of causative organisms according to regions among 501 episodes of peritonitis reported by the IPPR (with permission from [13])

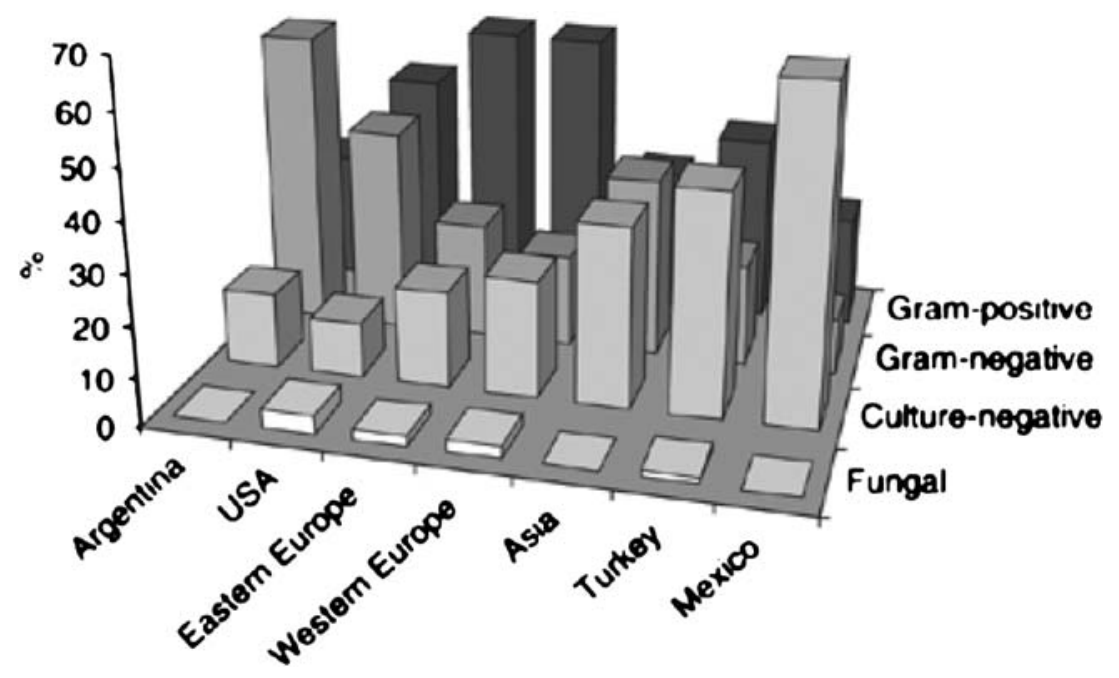

the latest IPPR report [14] and 3.1\% in the 2007 annual report of the NAPRTCS [2]. Yeasts belonging to the Candida genus are the most common fungal organisms implicated in peritonitis episodes. In the largest pediatric report addressing this infection, Candida species accounted for $79 \%$ of all fungal infections, with nearly $24 \%$ due to $C$. albicans and more than $26 \%$ secondary to $C$. parapsilopsis [37-39].

Mycobacterium tuberculosis is a very rare cause of peritonitis and requires a peritoneal biopsy for a definitive diagnosis [40]. Diphtheroid infections are most commonly the result of skin organisms contaminating the peritoneum by the intraluminal or periluminal route. Viruses have not been confirmed to be the primary cause of any episodes of peritonitis in pediatric CPD patients to date.

\section{Pathogenesis}

Peritonitis can result from bacteria reaching the peritoneum by one of several routes: transluminal (mainly touch contamination), periluminal (through an exit-site or tunnel infection), enteric, hematogenous and, but only rarely, ascending (through the vagina).

Coagulase-negative Staphylococcus characteristically infects the peritoneum by the transluminal route following touch contamination [28, 41]. The incubation period is typically $24-48 \mathrm{~h}$ but may be as short as 6-12 $\mathrm{h}$. This organism is also commonly associated with recurrent peritonitis due to biofilm formation. The decrease in the overall incidence of peritonitis experienced during the past decade is largely accounted for by a selective decrease in the frequency of infection caused by this organism.

Staphylococcus aureus infections are commonly associated with a catheter exit-site/tunnel infection with/without S. aureus nasal carriage $[28,41]$. In the IPPR data, $16 \%$ of
S. aureus peritonitis episodes were associated with $S$. aureus nasal carriage [14]. S. aureus is also commonly associated with recurrent peritonitis secondary to a catheter tunnel infection. Symptoms of $S$. aureus peritonitis are often more severe at presentation than those associated with coagulase-negative Staphylococcus, as demonstrated by disease severity score data collected by the IPPR, and clinical improvement is typically slower [14].

Streptococcus and Enterococcus generally account for fewer than 5\% of peritonitis episodes each [28]. Streptococci usually belong to the alpha-hemolytic group of bacteria and often cause peritonitis by hematogenous spread, either following a dental procedure or possibly originating from the respiratory tract, the skin, or the bowel. Enterococcal peritonitis is often severe; the organisms are fecal in origin, which often suggests a transmural route of infection. The emergence of vancomycin-resistant organisms in this species has been associated with an increased risk for patient mortality [42, 43].

Gram-negative infections are caused by a wide variety of organisms and are usually acquired by touch contamination, intra-abdominal pathology (e.g. ischemic colitis, ruptured appendicitis), or a catheter-related infection. The detection of enteric bacteria is indicative of fecal contamination, and intra-abdominal sources of infection should be suspected when multiple Gram-negative organisms are cultured. In this setting, anaerobic organisms should be looked for as well. Pseudomonas/Stenotrophomonas species are the most common Gram-negative species causing catheter exit-site and/or tunnel infections that result in peritonitis which can be extremely resistant to treatment [11, 15]. The organism may also form a biofilm on the catheter, thereby precluding successful antibiotic management without catheter removal. Gram-negative peritonitis is particularly troublesome as it commonly results in severe abdominal pain, is associated with dramatic alterations in the peri- 
toneal membrane transport capacity, and may result in technique failure [15, 44-46]. Finally, infections secondary to Acinetobacter may be an indication of contamination from a water source [47].

\section{Risk factors associated with peritonitis and preventive measures}

The cause of peritonitis in most cases is not obvious. Of the 491 episodes of non-fungal peritonitis recently analyzed by the IPPR, there were no identifiable factors associated with $72 \%$ of these. In the remainder, the most common causes were touch contamination ( $12 \%$ of all episodes), exit-site/ tunnel infection $(7 \%)$, and catheter perforation/leakage (2.1\%). The presence of a nasogastric tube, gastrostomy, and a ureterostomy was associated with 9.5, 7, and 5.5\% of the 491 episodes [14]. Apart from these identified factors, several other risk factors can heighten the incidence of peritonitis in children, and an understanding of these is important if one hopes to optimize prevention and patient outcome.

Patient age While it is well known that the rate of peritonitis in children is inversely related to age [2], recent IPPR data have confirmed for the first time a statistical association between young age and Gram-negative peritonitis $[14,15]$. The reasons for the increased incidence of infection in infants is not known, but it may in part be related to the proximity of the catheter exit-site to the diaper region or to gastrostomy/vesicostomy/nephrostomy sites $[14,48]$. In some centers, this issue has been successfully addressed by placing the PD catheter exit-site in a chest wall location $[49,50]$.

Catheter design Studies in children and adults have repeatedly demonstrated that the time to first peritonitis episode is significantly shorter and the peritonitis rate is significantly higher when a catheter with one cuff is used as opposed to a two-cuffed catheter $[4,51,52]$. The role of the superficial cuff in preventing infection is primarily one of anchoring the catheter to prevent trauma at the exit site [53]. The preferred catheter in children, from the standpoint of peritonitis risk, appears to be the double-cuffed swan neck catheter with its inherent downward directed exit-site. In fact, the NAPRTCS has demonstrated that the time to the first peritonitis episode is significantly longer with the latter PD access than with all other combinations of catheter characteristics [2]. Nevertheless, data to the contrary do exist [54-56].

Connection methodology The spiking of dialysis bags is a "high-risk" procedure because of the potential for contam- ination of the system. The introduction of double-bag, disconnect systems in CAPD, which eliminate the need for spiking and permit the flushing of the connection site and tubing with spent dialysate prior to the inflow of fresh dialysate, has contributed to a marked reduction in the incidence of peritonitis due to touch contamination. The "flush before fill" procedure has also proven to be beneficial in children and adults receiving APD [57, 58]. When spiking of bags is necessary, the Compact Assist Device (Baxter Healthcare, Deerfield, IL) may decrease the risk of contamination [59]. In the IPPR analysis, spiking connection systems were associated with an increased risk of acquiring Gram-negative peritonitis.

Prophylactic antibiotics A single dose of an intravenous antibiotic given at the time of catheter placement decreases the risk of a subsequent peritonitis episode [60-62]. While a first-generation cephalosporin has been most frequently used in this context, a single randomized trial did find that vancomycin was superior to a cephalosporin in preventing early peritonitis [60]. Prophylactic antibiotics are also indicated following intraluminal contamination and prior to dental procedures and procedures involving the gastrointestinal or urinary tract to decrease the risk of peritonitis $[11,60,63,64]$.

Catheter-related infections and exit-site care Catheter exitsite and tunnel infections, most often secondary to Staphylococcus or Pseudomonas, are associated with a significantly increased risk for the development of peritonitis [65-68]. It is important that, whenever possible, dialysis initiation be delayed for 1-2 weeks after catheter placement to allow for optimal surgical wound healing; failure to do so predisposes to dialysate leakage with an increased risk of infection. During the period of wound healing, dressing changes should ideally not occur more often than once per week and should be conducted by trained dialysis personnel using an aseptic technique [69, 70]. In children receiving CPD, colonization of the catheter exit-site with $S$. aureus and subsequent infection may not only originate from $S$. aureus nasal carriage of the patient [14, 71-74], but it may also come from family members and caretakers since as many as $45 \%$ of families with children on CPD have been found to have one or more members with evidence of nasal carriage [75]. A number of protocols for the prevention of $S$. aureus PD-related infections have been examined [10], and it has been reported that daily application of mupirocin cream to the skin around the exit site is a cost-effective approach to reducing $S$. aureus exit-site infection and peritonitis [76, 77]. However, emerging resistance to mupirocin and preferential Pseudomonas colonization of exit-sites treated with mupirocin has raised new concerns about this practice 
$[13,30,78-80]$. In fact, the IPPR data suggest that the global variation in Gram-negative peritonitis may well be a manifestation of exit-site care and mupirocin usage. The incidence of Pseudomonas peritonitis was eightfold higher in the USA than in Western Europe and was associated with exit-site care practices characterized by daily washing with non-sterile cleansing agents and the application of mupirocin [13]. In the latest IPPR report on Gramnegative peritonitis in children, $12 \%$ of the children with Gram-negative peritonitis had the same microorganism (most commonly Pseudomonas species) retrieved from the peritoneal fluid and exit-site, but less than half of these patients showed symptoms of a concurrent exit-site infection [15]. In turn, in a double-blinded randomized trial of adult CPD patients, gentamicin cream applied daily to the exit-site was found to be as effective as mupirocin in reducing $S$. aureus exit-site infections as well as highly effective in reducing Pseudomonas aeruginosa exit-site infections [81]. Similar data have not yet been collected in the pediatric population.

Training Training is an effective tool in reducing PD infections. Patients receiving CPD in Japan routinely experience very low peritonitis rates, probably as a result, at least in part, of prolonged (6-7 weeks) training sessions characterized by repetition and the understanding of PD principles. Similar data emerged from an international survey of 76 centers caring for children: the peritonitis rate was lowest in those centers who devoted longer periods of training to the topics of theory and practical/technical skills, all provided by experienced PD nurses [82]. Training issues may be particularly relevant to the $>10 \%$ of patients who develop peritonitis during the initial month of therapy [2]. Whereas the re-training of patients and caregivers should be considered following any episode of peritonitis, it is especially pertinent for patients with recurrent peritonitis [82].

Antibiotic usage A majority of fungal peritonitis episodes are preceded by a course(s) of antibiotics. A number of studies have examined the use of antifungal prophylaxis with either nystatin or fluconazole given during antibiotic therapy to prevent fungal peritonitis, with mixed results. Programs with high baseline rates of fungal peritonitis found such an approach to be beneficial, while those with low baseline rates did not detect a benefit [10, 38, 83-88].

Presence of gastrostomy While an earlier series of peritonitis episodes did not reveal any significant relationship between the presence of a gastrostomy and the development of fungal peritonitis in children [39], more recent IPPR data did reveal a nearly $(p=0.06)$ significant association between Gram-negative peritonitis and the presence of a gastrostomy [14].

\section{Presentation and diagnosis}

Peritoneal dialysis patients presenting with abdominal pain and/or cloudy effluent should be presumed to have peritonitis and evaluated for this infection. While a small percentage of pediatric and adult patients with peritonitis may present with clear effluent and abdominal pain [10, 14], the presence of a cloudy peritoneal effluent almost always indicates infectious peritonitis. However, there are a number of non-infectious causes of cloudy peritoneal effluent that should be recognized, including chemical peritonitis, eosinophilic peritonitis, hemoperitoneum, chylous ascites and, but only rarely, malignancy. As noted previously, the severity of the presentation of abdominal pain and fever in patients with peritonitis varies and is somewhat organism-specific; for example, the severity is generally mild-moderate with culture-negative peritonitis and peritonitis secondary to coagulase-negative Staphylococcus, whereas it is of greater severity with peritonitis resulting from Streptococcus, Gram-negative organisms, $S$. aureus, and fungi. An objective assessment of the severity of a patient's clinical status at presentation can be made by evaluating the Disease Severity Score (DSS, 0-5), which is defined by the sum of points for pain ( 0 , no pain; 1 , moderate pain or nausea not requiring specific therapy; 2 , severe pain, usually requiring analgesic therapy, or vomiting; 3 , peritoneal pain with a tense abdomen and/or paralytic bowel) and fever $\left(0,<37.5^{\circ} \mathrm{C} ; 1,37.5-38.9^{\circ} \mathrm{C} ; 2,>38.9^{\circ} \mathrm{C}\right)$ [89]. Data from the IPPR revealed that nearly half of the 121 Gram-negative peritonitis episodes occurred in children aged $<5$ years and the initial clinical manifestations were severe for the majority of patients [15].

The diagnosis of peritonitis is confirmed when the effluent white blood cell (WBC) count is $>100 / \mathrm{mm}^{3}$ and at least $50 \%$ of the WBCs are polymorphonuclear leukocytes. However, the recent analysis by the IPPR did reveal that the WBC count was $<100$ cells $/ \mu \mathrm{L}$ in $2.8 \%$ of clinical peritonitis episodes and that the percentage of polymorphonuclear cells was $<50 \%$ in $8.5 \%$ of cases [14]. These findings may be related to the fact that the number of cells in the effluent is partly dependent on the length of the exchange dwell. For patients on APD with short exchange dwell times, a second exchange with a dwell time of 1-2 $\mathrm{h}$ should be carried out, reexamined for turbidity and cell count, and sent for culture when peritonitis is suspected.

It is imperative that the diagnostic work-up of peritonitis is performed according to a standardized protocol $[10,11]$ as the correct culture techniques of peritoneal effluent are of utmost importance for establishing the microorganism responsible for the infection. The identification of both the organism and subsequent antibiotic sensitivities not only assists the clinician in selecting the most effective antibiotic, but it can also help identify the possible source 
of the infection. For details on the various culturing techniques, the reader is referred to the ISPD guidelines from 2000 and 2005 [10, 11]. When a standard culture technique is used, culture-negative peritonitis should not account for $>20 \%$ of all peritonitis episodes, and centers with higher rates should review and improve their culture methodology [10].

\section{Management of peritonitis}

\section{General guidelines}

To prevent a delay in treatment, antibiotic therapy should be initiated as soon as the diagnosis of peritonitis is suspected and after samples of the dialysis effluent are obtained for Gram stain, cell count and culture; if signs of severe infection, such as pain and fever are present, it is often advisable not to wait for confirmation of the cell count from the laboratory. Several rapid flushes with dialysis solution may be performed prior to the initiation of antibiotic therapy to help reduce the severity of the abdominal pain. In this case, because therapy is initiated prior to knowledge of the causative organism, initial empirically chosen antibiotics must cover both Grampositive and Gram-negative organisms.

Antibiotics selected for the treatment of peritonitis should be administered intraperitoneally to ensure immediate bioavailability, and recommendations for continuous (provided in each exchange) and intermittent dosing are available (Table 1) [11]. While evidence exists for the efficacy of intermittent dosing of aminoglycosides, glycopeptides, and the third-generation cephalosporin ceftazidime, most of this information is derived from adult patients on CAPD [90-92]. In a randomized trial in children that included both CAPD and APD patients, intermittent dosing of a glycopeptide was as efficacious as continuous dosing in patients with Gram-positive peritonitis, while intermittent ceftazidime dosing in cases with Gram-negative peritonitis was less successful than continuous treatment according to clinical judgment, but not by the objective DSS criteria [89]. The recent IPPR analysis of 121 episodes of Gram-negative peritonitis revealed a 14-fold increased risk of empiric treatment failure associated with intermittent ceftazidime therapy in comparison to continuous ceftazidime therapy and also questions the advisability of the former approach [15]. When intermittent dosing is used, the antibiotic-containing dialysis solution must be allowed to dwell for at least $6 \mathrm{~h}$ to allow adequate absorption of the antibiotic into the systemic circulation, which permits subsequent reentry into the peritoneal cavity during ensuing fresh dialysis solution exchanges. The rapid exchanges that often characterize APD in children may be associated with an inadequate time to achieve therapeutic intraperitoneal levels by the reentry mechanism, and dwell times may need to be prolonged in these situations. A recent pediatric study that evaluated the disposition of intraperitoneal vancomycin in children has suggested that an enhanced total body vancomycin elimination (relative to adults) coupled with a slow peritoneal transfer, should prompt reevaluation of the current recommendation for intermittent vancomycin therapy, particularly in children receiving short-dwell PD regimens [93].

Even when continuous intraperitoneal antibiotic dosing is used for children on APD, the dwell times should likely be prolonged to $3-6 \mathrm{~h}$ for the initial $24-48 \mathrm{~h}$ of the therapy until there is clearing of the peritoneal effluent. The prolongation of the dwell time helps prevent depletion of the cellular components of the local host defense mechanism that may occur with frequent exchanges [94, 95]. However, prolongation of the dwell time may not be necessary/advisable for asymptomatic patients or for those with compromised ultrafiltration capacity and a need for more frequent exchanges to maintain euvolemia.

It is recommended that the antibiotic containing dwell, irrespective of whether the patient routinely receives CAPD or APD, should be a full volume exchange (approximately $1100 \mathrm{~mL} / \mathrm{m}^{2}$ body surface area) during both day and nighttime; in situations in which the exchange volume is decreased during the initial $24-48 \mathrm{~h}$ of therapy because of abdominal pain, the concentration of antibiotics must be increased to ensure the infusion of the same mass of the antibiotics that would be provided in a full dwell volume [11]. The dose of any antibiotic that undergoes renal excretion may also need to be increased in those patients with residual kidney function [11].

Adjuvant therapy Patients with extremely cloudy effluent may benefit from the addition of low-dose heparin (500 $1000 \mathrm{U} / \mathrm{L}$ ) into the dialysate as it can help prevent occlusion of the catheter due to fibrin, which is often present as a result of the inflammatory process [96]. As infants receiving CPD with peritonitis can lose substantial amounts of gamma globulin across an inflamed peritoneum, they may benefit from intravenous immunoglobulin (Ig) therapy, especially if they have low measured IgG levels and/or they appear septic [97, 98].

\section{Antibiotic therapy}

Initial (empiric) therapy The current pediatric peritonitis treatment guidelines recommend the combination of either a first-generation cephalosporin, such as cefazolin, or a glycopeptide (vancomycin or teicoplanin) with a thirdgeneration cephalosporin, such as ceftazidime [11]. The 
Table 1 Antibiotic dosing recommendations. Administration should be via intraperitoneal route unless specified otherwise

\begin{tabular}{|c|c|c|c|}
\hline \multirow[t]{2}{*}{ Antibiotics } & \multicolumn{2}{|l|}{ Continuous therapy } & \multirow[t]{2}{*}{ Intermittent therapy ${ }^{\mathrm{b}}$} \\
\hline & Loading dose $^{\mathrm{a}}$ & Maintenance dose & \\
\hline \multicolumn{4}{|l|}{ Glycopeptides } \\
\hline Vancomycin & $1000 \mathrm{mg} / \mathrm{L}$ & $25 \mathrm{mg} / \mathrm{L}$ & $30 \mathrm{mg} / \mathrm{kg}$ q 5-7 days \\
\hline Teicoplanin ${ }^{\mathrm{c}}$ & $400 \mathrm{mg} / \mathrm{L}$ & $20 \mathrm{mg} / \mathrm{L}$ & $15 \mathrm{mg} / \mathrm{kg} \mathrm{q} \mathrm{5-7} \mathrm{days}$ \\
\hline \multicolumn{4}{|l|}{ Cephalosporins } \\
\hline Cefazolin/Cephalothin & $500 \mathrm{mg} / \mathrm{L}$ & $125 \mathrm{mg} / \mathrm{L}$ & $15 \mathrm{mg} / \mathrm{kg} \mathrm{q} 24 \mathrm{~h}$ \\
\hline Cefuroxime & $200 \mathrm{mg} / \mathrm{L}$ & $125 \mathrm{mg} / \mathrm{L}$ & $15 \mathrm{mg} / \mathrm{kg} \mathrm{q} 24 \mathrm{~h}$ \\
\hline Cefotaxime & $500 \mathrm{mg} / \mathrm{L}$ & $250 \mathrm{mg} / \mathrm{L}$ & $30 \mathrm{mg} / \mathrm{kg} \mathrm{q} 24 \mathrm{~h}$ \\
\hline Ceftazidime & $250 \mathrm{mg} / \mathrm{L}$ & $125 \mathrm{mg} / \mathrm{L}$ & $15 \mathrm{mg} / \mathrm{kg} \mathrm{q} 24 \mathrm{~h}$ \\
\hline Ceftizoxime & $250 \mathrm{mg} / \mathrm{L}$ & $125 \mathrm{mg} / \mathrm{L}$ & - \\
\hline \multicolumn{4}{|l|}{ Antifungals } \\
\hline Amphotericin B & $1 \mathrm{mg} / \mathrm{kg} \mathrm{IV}$ & $1 \mathrm{mg} / \mathrm{kg} /$ day IV & - \\
\hline Fluconazole & - & - & $\begin{array}{l}3-6 \mathrm{mg} / \mathrm{kg} \text { IP, IV or PO q } \\
24-48 \mathrm{~h}(\max . \text { dose } 200 \mathrm{mg})\end{array}$ \\
\hline Flucytosine & $\begin{array}{c}50 \mathrm{mg} / \mathrm{kg} \text { IV or PO } \\
(\mathrm{max} . \text { dose } 2.0 \mathrm{~g})\end{array}$ & $\begin{array}{l}25-37.5 \mathrm{mg} / \mathrm{kg} \mathrm{PO} / \mathrm{day} \\
(\max . \text { dose } 1.0 \mathrm{~g})\end{array}$ & - \\
\hline \multicolumn{4}{|l|}{ Aminoglycosides ${ }^{\mathrm{d}}$} \\
\hline Amikacin & $25 \mathrm{mg} / \mathrm{L}$ & $12 \mathrm{mg} / \mathrm{L}$ & - \\
\hline Gentamicin & $8 \mathrm{mg} / \mathrm{L}$ & $4 \mathrm{mg} / \mathrm{L}$ & - \\
\hline Netilmicin & $8 \mathrm{mg} / \mathrm{L}$ & $4 \mathrm{mg} / \mathrm{L}$ & - \\
\hline Tobramycin & $8 \mathrm{mg} / \mathrm{L}$ & $4 \mathrm{mg} / \mathrm{L}$ & - \\
\hline \multicolumn{4}{|l|}{ Penicillins ${ }^{\mathrm{d}}$} \\
\hline Azlocillin & $500 \mathrm{mg} / \mathrm{L}$ & $250 \mathrm{mg} / \mathrm{L}$ & - \\
\hline Piperacillin & - & $250 \mathrm{mg} / \mathrm{L}$ & $150 \mathrm{mg} / \mathrm{kg} \mathrm{IV} \mathrm{q} 12 \mathrm{~h}$ \\
\hline Ampicillin & - & $125 \mathrm{mg} / \mathrm{L}$ & - \\
\hline Oxacillin & - & $125 \mathrm{mg} / \mathrm{L}$ & - \\
\hline Nafcillin & - & $125 \mathrm{mg} / \mathrm{L}$ & - \\
\hline Amoxicillin & $250-500 \mathrm{mg} / \mathrm{L}$ & $50 \mathrm{mg} / \mathrm{L}$ & - \\
\hline \multicolumn{4}{|l|}{ Quinolones } \\
\hline Ciprofloxacin & $50 \mathrm{mg} / \mathrm{L}$ & $25 \mathrm{mg} / \mathrm{L}$ & - \\
\hline \multicolumn{4}{|l|}{ Combinations } \\
\hline Ampicillin/Sulbactam & $1000 \mathrm{mg} / \mathrm{L}$ & $100 \mathrm{mg} / \mathrm{L}$ & - \\
\hline Imipenem/Cilastatin & $500 \mathrm{mg} / \mathrm{L}$ & $200 \mathrm{mg} / \mathrm{L}$ & - \\
\hline Trimethoprim/sulfamethoxazole & $320 / 1600 \mathrm{mg} / \mathrm{L}$ & $80 / 400 \mathrm{mg} / \mathrm{L}$ & - \\
\hline \multicolumn{4}{|l|}{ Others } \\
\hline Clindamycin & $300 \mathrm{mg} / \mathrm{L}$ & $150 \mathrm{mg} / \mathrm{L}$ & - \\
\hline Metronidazole & - & - & $35-50 \mathrm{mg} / \mathrm{kg} /$ day PO in 3 doses \\
\hline Rifampin & - & - & $20 \mathrm{mg} / \mathrm{kg} /$ day PO (max. dose $600 \mathrm{mg} /$ day) \\
\hline Aztreonam & $1000 \mathrm{mg} / \mathrm{L}$ & $250 \mathrm{mg} / \mathrm{L}$ & - \\
\hline
\end{tabular}

q, Every day; IV, Intravenously; IP, intraperitoneally; PO, orally

The therapeutic recommendations provided in this table are those of the ISPD Advisory Committee on Peritonitis Management in Pediatric Patients and are, in large part, based upon adult experiences (used with permission from [11])

${ }^{a}$ Loading dose should be administered during a standardized 3- to 6-h dwell period. Concentration-related loading doses assume usual patientspecific fill volume (i.e. approximately $1100 \mathrm{~mL} / \mathrm{m}^{2}$ body surface area). If a smaller volume is instilled, the concentration must be increased to ensure infusion of an equal mass of antibiotic. Intermittent antibiotic dosing should be administered over $\geq 6 \mathrm{~h}$ in one bag per day for continuous ambulatory peritoneal dialysis (CAPD) patients, or during a full fill volume daytime dwell for automated peritoneal dialysis (APD) patients, unless otherwise specified

${ }^{\mathrm{b}}$ Accelerated glycopeptide elimination may occur in patients with residual renal function. Intermittent therapy is used in this setting. The second dose of antibiotic should be time-based on a blood level obtained 3-5 days after the initial dose. Redosing should occur when the blood level is $<12 \mathrm{mg} / \mathrm{L}$ for vancomycin or $8 \mathrm{mg} / \mathrm{L}$ for teicoplanin. Intermittent therapy is not recommended for patients with residual renal function unless serum drug levels can be monitored in a timely manner

${ }^{\mathrm{c}}$ Teicoplanin is not currently available in the USA

${ }^{\mathrm{d}}$ Aminoglycosides and penicillins should not be mixed in dialysis fluid because of the potential for inactivation 
recommendation of a glycopeptide and ceftazidime combination in "high-risk patients" or those thought to be at high risk for severe disease based on their young age, a history of $S$. aureus infection, or a history of a recent catheterrelated infection was based on the increasing prevalence of methicillin resistance and the expected severe clinical course in these patients. The decision was also influenced by the superiority of this combination in a meta-analysis of studies performed in adults and it's safety and efficacy profile in children $[29,89,99-101]$. The recommendation is, however, that glycopeptide usage be restricted to highrisk patients because of the fear of promoting vancomycinresistant enterococci and the potential emergence of glycopeptide-resistant staphylococci [42, 43, 102-104]. Finally, the choice of ceftazidime over aminoglycosides was influenced by the potential for a high cumulative exposure to the latter, with possible resultant ototoxicity and nephrotoxicity [105]. The latter assumes significance in view of the considerable residual kidney function that is commonly present in children with hypoplastic kidney disorders and that may have a positive impact on patient outcome [106-108].

Once culture results and sensitivities are known, antibiotic therapy should be adjusted appropriately. The current pediatric peritonitis treatment guidelines for therapy modification according to dialysate culture results are as follows:

- Gram-positive peritonitis. The empiric use of ceftazidime should be discontinued. For methicillin-sensitive staphylococci, the first generation cephalosporin should be continued or should replace the empiric glycopeptide. For patients with methicillin-resistant staphylococci, a glycopeptide (vancomycin or teicoplanin) should be continued or should replace the first-generation cephalosporin. Clindamycin is a satisfactory alternative for those who do not tolerate glycopeptide antibiotics. Ampicillin is a suitable monotherapy for peritonitis caused by enterococci and streptococci and can be replaced with clindamycin or a glycopeptide if organisms are resistant to ampicillin. Treatment duration should be 2 weeks for all organisms except $S$. aureus, for which therapy should be 3 weeks [11].

- Gram-negative peritonitis. Upon culture of a single Gramnegative organism, the first-generation cephalosporin or glycopeptide should be discontinued and ceftazidime continued if the organism is sensitive to ceftazidime and the patient is responding well clinically. However, if the organism belongs to the Pseudomonas/Stenotrophomonas genus, a second antibiotic with synergistic activity (e.g. an aminoglycoside) should be added. If multiple Gramnegative organisms or anaerobic bacteria are grown, metronidazole should be added and the patient should be investigated for intra-abdominal pathology. The recommended duration of treatment is 3 weeks for Pseudomonas/Stenotrophomonas species, multiple organisms, and/ or anaerobic organisms, and 2 weeks for other single Gram-negative organisms [11].

- Culture-negative peritonitis. In cases where the culture remains sterile and the patient's clinical condition is improving, combined empiric therapy should be continued for 2 weeks [11]. However, prolonged therapy with an aminoglycoside is discouraged because of the concern for toxicity.

The recent analysis of 491 episodes of non-fungal peritonitis by the IPPR has provided the opportunity to evaluate the efficacy of the recommendations regarding antibiotic therapy [14]. Of interest, the analysis did not support the earlier opinion-based recommendation of assigning young infants as well as children with a severe clinical presentation, previous or ongoing exit-site infection, or a methicillin-resistant $S$. aureus history preferentially to glycopeptide treatment, as no significant correlation was seen between the presence of the previously described risk factors, the empiric antibiotic therapy chosen, and either the early treatment response or the final functional outcome. The reason for this inconsistency was primarily due to significant in vitro resistance to ceftazidime in patients with Gramnegative peritonitis. This group of patients responded better clinically to a combination of a first-generation and third-generation cephalosporin than to a combination of ceftazidime and a glycopeptide, likely due to a manifestation of synergy between the former pair of antibiotics (vide infra). Overall, only $80 \%$ of Gram-negative organisms showed in vitro sensitivity to ceftazidime, whereas the proportion of sensitive organisms increased to $91 \%$ for the combination of a first-generation and thirdgeneration cephalosporin and to $93 \%$ for the combination of a first-generation cephalosporin and an aminoglycoside. The sensitivity of Gram-negative organisms to aminoglycosides varied globally, ranging from $82 \%$ in Eastern Europe to $96 \%$ in Western Europe [13].

The sensitivity of Gram-positive organisms to glycopeptide antibiotics was consistently high (96-100\%), but their sensitivity to a first-generation cephalosporin varied by country-from $50 \%$ in the USA to $94 \%$ in Eastern Europe. Overall, only $69 \%$ of Gram-positive organisms were sensitive to either cefazolin or cephalothin, and the combined sensitivity increased to $94 \%$ when an aminoglycoside was combined with the former antibiotic. In vitro evaluation revealed that $50 \%$ of the coagulase negative staphylococci and $14 \%$ of the $S$. aureus strains were resistant to methicillin. Finally, $90 \%$ of the Gram-positive organisms tested and $96 \%$ of the Gram-negative organisms tested were sensitive to ciprofloxacin [14]. 
This heretofore unrecognized variability in antibiotic susceptibility is likely the result of antibiotic preferences in different regions, which in turn are influenced by local experience and treatment guidelines, cost considerations and, at least for some drugs, availability issues and marketing activities. These issues and the data collected by the IPPR support the latest ISPD recommendations that the empiric antibiotic therapy of peritonitis should take into account the patient- and center-specific history of microorganisms and their sensitivity pattern [10, 109]. Antibiotic resistance patterns should be monitored on a regular basis, and the treatment protocol should cover all serious pathogens that are prevalent in that region. The limited success in treating Gram-negative infections with ceftazidime, the substantial morbidity associated with these infections, and the greater susceptibility of Gram-negative organisms to aminoglycosides emphasize the importance of considering possible modification of current empiric antibiotic therapy recommendations. While repeated or prolonged courses of aminoglycoside therapy are likely not advisable, their short-term use appears to be safe and without detrimental effect on residual kidney function [110]. When the aminoglycoside antibiotic is used as part of the empiric regimen, there should be prompt modification of antibiotic management once susceptibility data reveal that the causative organism is resistant to that aminoglycoside antibiotic or that another, less toxic antibiotic displays evidence of equivalent in vitro efficacy. In the case of culture-negative peritonitis, substitution of the aminoglycoside with ceftazidime is likely to be preferable.

Although the IPPR data suggests that ciprofloxacin may be an ideal single agent, providing broad spectrum coverage against both Gram-positive and Gram-negative organisms, the potential for rapid development of bacterial resistance and the possible risk of interference with cartilage development in young children make this a less desirable choice for initial therapy $[111,112]$.

\section{Assessment of initial response}

The patient's clinical condition should be assessed daily subsequent to the initiation of therapy. An assessment of the dialysis effluent after 3 days of therapy will typically reveal the dialysate leukocyte count to have decreased by more than $50 \%$, with a shift from a predominance of polymorphonuclear to mononuclear cells. It is noteworthy that, on occasion, microorganisms may still grow in the peritoneal cavity after $72 \mathrm{~h}$ of treatment, particularly in patients receiving intermittent antibiotic administration. These positive cultures, however, do not predict a poor outcome [89].

Failure to respond within $72 \mathrm{~h}$ of therapy initiation should prompt further investigation, including a repeat assessment of the dialysate cell count, Gram stain, and culture, an assessment of the catheter tunnel and exit-site by clinical and, possibly, ultrasound evaluation, and an exitsite culture $[113,114]$.

\section{Management of refractory peritonitis}

The most common cause of treatment-resistant peritonitis is a catheter tunnel-related infection, usually due to a $S$. aureus or $P$. aeruginosa infection of the subcutaneous tissue around the catheter cuffs $[11,115]$. The confirmation of a tunnel infection in therapy-resistant peritonitis necessitates immediate removal of the catheter, followed by $2-3$ weeks of temporary hemodialysis and intravenous antibiotic therapy before a new catheter can be inserted, preferably on the contralateral side [11].

In patients whose peritoneal fluid culture is positive for anaerobic bacteria or multiple Gram-negative organisms, the possibility of intra-abdominal pathology (e.g. ruptured appendix) should be considered. Another possible explanation of antibiotic-resistant peritonitis is fungal infection, which usually develops following antibiotic treatment of bacterial peritonitis but can occur without any risk factors in a substantial number of patients [37-39]. If fungi are identified by Gram stain or culture, all antibiotics should be discontinued and antimycotic treatment initiated with either intravenous amphotericin B or a combination of an imidazole/triazole (e.g. intravenous or oral fluconazole) and flucytosine (if available). Whereas amphotericin B has historically been recommended as the primary treatment for fungal peritonitis in patients receiving $\mathrm{PD}$, data collected in children and adults provide evidence that the peritoneal penetration of amphotericin B following systemic administration is poor [116]. In contrast, fluconazole is characterized by excellent bioavailability and peritoneal penetration and is almost always active against Candida species [117]. Unfortunately, fungi usually colonize the surface of the silastic material of the catheter, thereby making medical therapy rather futile. Accordingly, in virtually all circumstances, the prognosis for successful management of the infection and for the potential of ongoing PD will be improved by immediate catheter removal [10]. Antimycotic treatment should be continued during temporary hemodialysis for at least 2 weeks after the complete resolution of clinical symptoms and before placement of a new PD catheter is considered [11].

\section{Relapsing peritonitis}

Relapsing peritonitis is defined as the recurrence of peritonitis with the same organism as in the immediately 
preceding episode according to culture results and antibiotic susceptibilities, within 4 weeks of completion of antibiotic treatment. Relapsing peritonitis may occur in up to $20 \%$ of initially antibiotic-responsive Gram-positive peritonitis episodes. The most common microorganisms causing relapsing peritonitis are slime-forming coagulase-negative staphylococci that can survive antibiotic treatment in fibrinous adhesions and in the biofilm matrix on the catheter surface [118]. Staphylococcus aureus and $P$. aeruginosa, which may cause subclinical microabscesses in the tunnel region or in intra-abdominal adhesions, may also be the source of this complication. Ultrasound assessment can assist in the detection of clinically occult tunnel infections [119].

Since the causative organism of relapsing peritonitis is not known when clinical symptoms occur, empiric treatment should be reinitiated initially. After confirmation of the relapse by culture and antibiotic susceptibilities, organismspecific treatment should be continued for 3 weeks. Early catheter removal is recommended in cases where the origin of the re-infection can be localized to the catheter tunnel and in any case of a relapsing infection with Pseudomonas or Stentrophomonas species.

\section{Catheter removal and reinsertion}

Peritoneal dialysis catheter removal should be seen as part of the recommended peritonitis management in situations in which failure to do so is unlikely to result in a successful outcome. The primary goal in managing peritonitis should always be the optimal treatment of the patient and protection of the peritoneum - and not saving the catheter. Whereas there are no data to permit an evidence-based recommendation with respect to the length of antibiotic treatment following catheter removal and the appropriate time for catheter replacement, an interval of 2-3 weeks between catheter removal and catheter replacement with at least 2 weeks of systemic antibiotic therapy during the intervening period is considered to be acceptable [11]
Simultaneous catheter removal and reinsertion can, on occasion, obviate the need for interval hemodialysis and has been successfully reported in cases with recurrent peritonitis, relapsing peritonitis (unless caused by Pseudomonas/Stentrophomonas species), and refractory exit-site or tunnel infections, including those caused by Pseudomonas species [120123]. In patients with refractory exit-site infection, timely replacement of the catheter can decrease the risk of peritonitis. Catheter exchange associated with peritonitis should be performed once the infection has responded to antibiotics and the effluent cell count is $<100$ leukocytes/ $\mu 1$ [124], and this procedure should be followed by 3 weeks of appropriate antibiotic therapy. Simultaneous catheter removal and reinsertion is not advocated for refractory and fungal peritonitis.

\section{Final outcome}

Peritonitis is the primary reason for technique failure in children receiving CPD. According to the 2007 NAPRTCS annual report, 675 patients entered in the dialysis registry discontinued PD for reasons other than transplantation, with excessive infection being the primary reason for discontinuation in $42.8 \%$ of these cases [2].

Based on the IPPR experience, $89 \%$ of peritonitis episodes were followed by full functional recovery (Fig. 3). Peritoneal dialysis was permanently discontinued (technique failure) in $8.1 \%$ of cases because of persistent ultrafiltration problems, abdominal adhesions, persistent infection, secondary development of fungal peritonitis, or general therapy failure. The outcome of infections caused by Pseudomonas species tended to be the least favorable, with only $74 \%$ of the cases achieving full recovery. When outcome was compared by geographic region, the final outcome was significantly less favorable in Eastern Europe, where PD was permanently discontinued in $20 \%$ of patients. This poor outcome was associated with the preferential usage of straight rather than coiled Tenckhoff catheters, a practice that may predispose to inferior drainage in patients with post-peritonitic adhesions [13]. Relapsing peritonitis occurred in 52 cases, and full
Fig. 3 Peritonitis outcome by organisms as reported by the IPPR (with permission from [14]). Coag. Neg. Staph coagulase-negative Staphylococcus

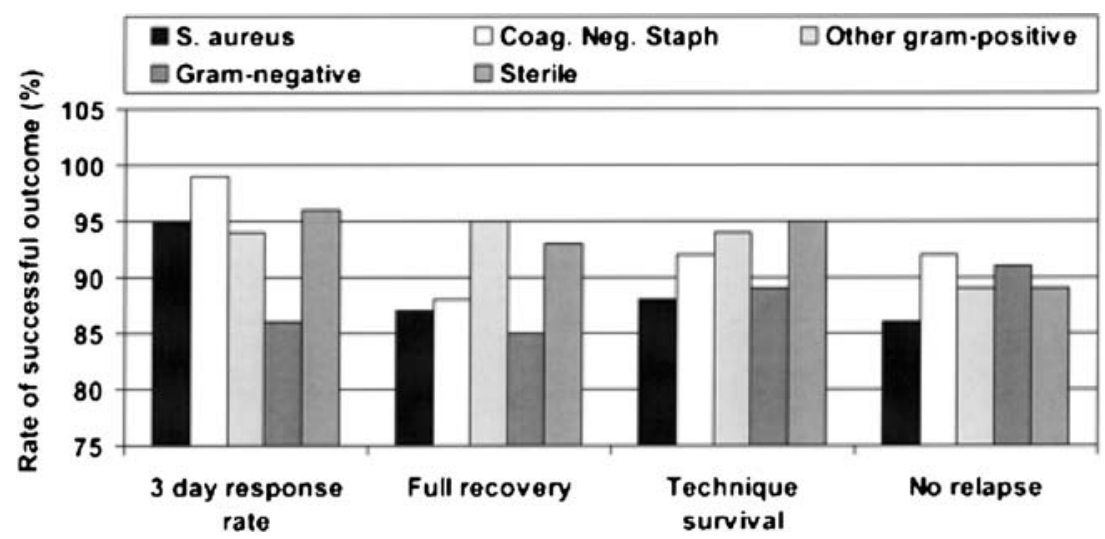


recovery was also less common in this group of patients (75\%) than in those who had episodes without relapse (91\%) [14].

The mortality rate in children who develop acute peritonitis is approximately $1 \%$ [125]. Six deaths were reported by the IPPR, representing $1.2 \%$ of the peritonitis episodes. Three of these deaths were associated with the development of Gram-negative peritonitis. Repeated episodes of peritonitis have been associated with patient mortality following the development of sclerosing encapsulating peritonitis $[126,127]$.

\section{Concluding paragraph}

Peritonitis remains the most significant complication of PD in children. New technologies and a better understanding of the epidemiology of the infection should result in greater success in terms of prevention and treatment, with resultant preservation of $\mathrm{PD}$ as a viable long-term dialysis modality for the pediatric patient.

\section{Questions}

(Answers are given following the questions)

1. The microbiology of peritoneal dialysis-associated peritonitis is best characterized by which of the following?
A. $50-60 \%$ Gram-positive organisms and $25 \%$ fungi
B. $50-60 \%$ Gram-positive organisms and $20-30 \%$ Gram-negative organisms
C. 50-60\% Gram-negative organisms, 5\% Gram- positive organisms, and $25 \%$ culture negative
D. $50-60 \%$ Gram-negative, $25 \%$ culture-negative, and $15 \%$ viral
E. $50-60 \%$ Gram-positive organisms, $20 \%$ fungi, and $30 \%$ culture-negative

2. Which one of the routes listed below is not a common route by which bacteria may reach the peritoneum and cause peritoneal dialysis-associated peritonitis?
A. Hematogenous
B. Periluminal
C. Enteric
D. Transluminal
E. Transhepatic

3. Which of the following organisms are frequently associated with catheter exit-site and tunnel infections and may predispose to the development of peritonitis?
A. Escherichia coli
B. Klebsiella
C. Acinetobacter
D. Pseudomonas
E. Streptococcus

4. The dialysis effluent cell count characteristic of peritoneal dialysis associated bacterial peritonitis is which of the following?
A. Greater than $100 / \mathrm{mm}^{3}$ WBC with at least $50 \%$ polymorphonuclear leukocytes
B. Greater than $1000 / \mathrm{mm}^{3}$ WBC with at least $15 \%$ polymorphonuclear leukocytes
C. Greater than $50 / \mathrm{mm}^{3}$ WBC with at least $15 \%$ eosinophils
D. Greater than $100 / \mathrm{mm}^{3}$ WBC with fewer than $50 \%$ polymorphonuclear leukocytes
E. Less than $100 / \mathrm{mm}^{3}$ WBC with more than $50 \%$ lymphocytes

5. The IPPR has recently found that the in vitro sensitivity of Gram-positive organisms to a first-generation cephalosporin is which of the following?
A. $100 \%$
B. $85 \%$
C. $69 \%$
D. $10 \%$
E. $35 \%$

\section{References}

1. Alexander SR, Warady BA (2004) The demographics of dialysis in children. In: Warady BA, Schaefer FS, Fine RN, Alexander SR (eds) Pediatric dialysis. Kluwer, Dordrecht, pp 35-46

2. North American Pediatric Renal Trials and Cooperative Studies (NAPRTCS) (2007) 2007 Annual report. EMMES Corp, Rockville

3. Szeto CC, Chow KM, Wong TY, Leung CB, Li PK (2003) Influence of climate on the incidence of peritoneal dialysisrelated peritonitis. Perit Dial Int 23:580-586

4. Warady BA, Sullivan EK, Alexander SR (1996) Lessons from the peritoneal dialysis patient database: a report of the North American Pediatric Renal Transplantation Cooperative Study. Kidney Int 53:S68-S71

5. Tranaeus A (1998) Peritonitis in pediatric continuous peritoneal dialysis. In: Fine RN, Alexander S, Warady BA (eds) CAPD/ CCPD in children. Kluwer, Norwell, pp 301-347

6. U.S. Renal Data System (USRDS) (2007) 2007 Annual data report: atlas of end-stage renal disease in the United States. National Institute of Health, National Institute of Diabetes and Digestive and Kidney Diseases, Bethesda

7. Keane WF, Everett ED, Golper TA, Gokal R, Halstenson C, Kawaguchi Y, Riella M, Vas S, Verbrugh HA (1993) Peritoneal dialysis-related peritonitis treatment recommendations: 1993 update. The Ad Hoc Advisory Committee on Peritonitis Management. International Society for Peritoneal Dialysis. Perit Dial Int 13:14-28

8. Keane WF, Alexander SR, Bailie GR, Boeschoten E, Gokal R, Golper TA, Holmes CJ, Huang CC, Kawaguchi Y, Piraino B, 
Riella M, Schaefer F, Vas S (1996) Peritoneal dialysis-related peritonitis treatment recommendations: 1996 update. Perit Dial Int 16:557-573

9. Keane WF, Bailie GR, Boeschoten E, Gokal R, Golper TA, Holmes CJ, Kawaguchi Y, Piraino B, Riella M, Vas S (2000) Adult peritoneal dialysis-related peritonitis treatment recommendations: 2000 update. Perit Dial Int 20:828-829

10. Piraino B, Bailie GR, Bernardini J, Boeschoten E, Gupta A, Holmes C, Kuijper EJ, Li PKT, Lye WC, Mujais S, Paterson DL, Fontan MP, Ramos A, Schaefer F, Uttley L (2005) Peritoneal dialysis-related infections recommendations: 2005 update. Perit Dial Int 25:107-131

11. Warady BA, Schaefer F, Holloway M, Alexander S, Kandert M, Piraino B, Salusky I, Tranaeus A, Divino J, Honda M, Mujais S, Verrina $\mathrm{E}$, for the International Society for Peritoneal Dialysis (ISPD) (2000) Advisory Committee on Peritonitis Management in Pediatric Patients: consensus guidelines for the treatment of peritonitis in pediatric patients receiving peritoneal dialysis. Perit Dial Int 20:610-624

12. Feneberg R, Warady BA, Alexander SR, Schaefer F, Members of the International Pediatric Peritoneal Registry (2004) The International Pediatric Peritoneal Registry: a global internetbased initiative in pediatric dialysis. Perit Dial Int 24:S130-S134

13. Schaefer F, Feneberg R, Aksu N, Donmez O, Sadikoglu B, Alexander SR, Mir S, Ha IS, Fischbach M, Simkova E, Watson AR, Moller K, von Baum H, Warady BA (2007) Worldwide variation of dialysis-associated peritonitis in children. Kidney Int 72:1374-1379

14. Warady BA, Feneberg R, Verrina E, Flynn JT, Muller-Wiefel DE, Besbas N, Zurowska A, Aksu N, Fischbach M, Sojo E, Donmez O, Sever L, Sirin A, Alexander SR, Schaefer F (2007) Peritonitis in children who receive long-term dialysis: a prospective evaluation of therapeutic guidelines. J Am Soc Nephrol 18:2172-2179

15. Zurowska A, Feneberg R, Warady BA, Zimmering $M$, Monteverde M, Testa S, Calyskan S, Drozdz D, Salusky I, Kemper MJ, Ekim M, Verrina E, Misselwitz J, Schaefer F (2008) Gram-negative peritonitis in children undergoing longterm peritoneal dialysis. Am J Kidney Dis 51:455-462

16. Burkart J, Hylnader B, Durnell-Figel T, Roberts D (1990) Comparison of peritonitis rates during long-term use of standard spike versus Ultraset in continuous ambulatory peritoneal dialysis (CAPD). Perit Dial Int 10:41-43

17. Burkart J, Jordan JR, Durnell TA, Case LD (1992) Comparison of exit-site infections in disconnect versus nondisconnect systems for peritoneal dialysis. Perit Dial Int 12:317-320

18. Valeri A, Radhakrishnan J, Vernocci L, Carmichael LD, Stern L (1993) The epidemiology of peritonitis in acute peritoneal dialysis: A comparison between open- and closed-drainage systems. Am J Kidney Dis 21:300-309

19. Monteon F, Correa-Rotter R, Paniagua R, Amato D, Hurtado ME, Medina JL, Salcedo RM, Garcia E, Matos M, Kaji J, Vazquez R, Ramos A, Schettino MA, Moran J (1998) Prevention of peritonitis with disconnect systems in CAPD: A randomized controlled trial. Kidney Int 54:2123-2128

20. Li PK, Law MC, Chow KM, Chan WK, Szeto CC, Cheng YL, Wong TY, Leung CB, Wang AY, Lui FS, Yu AW (2002) Comparison of clinical outcome and ease of handling in two double-bag systems in continuous ambulatory peritoneal dialysis: a prospective, randomized controlled, multicenter study. Am J Kidney Dis 40:373-380

21. Kim DK, Yoo TH, Ryu DR, Xu ZG, Kim HJ, Choi KH, Lee HY, Han DS, Kang SW (2004) Changes in causative organisms and their antimicrobial susceptibilities in CAPD peritonitis: a single center's experience over one decade. Perit Dial Int $24: 424-432$
22. Benfield MR, McDonald R, Sullivan EK, Stablein DM, Tejani A (1999) The 1997 annual renal transplantation in children: Report of the North American Pediatric Renal Transplant Cooperative Study (NAPRTCS). Pediatr Transplant 2:152-167

23. Verrina E, Bassi S, Perfumo F, Edefonti A, Zacchello G, Andreetta B, Pela I, Penza R, Piaggio G, Picca M (1993) Analysis of complications in a chronic peritoneal dialysis pediatric patient population. The Italian Registry of Pediatric Patient Population. Perit Dial Int 13:S257-S259

24. Schaefer F, Klaus G, Muller-Wiefel DE, Mehls O (1999) Current practice of peritoneal dialysis in children: Results of a longitudinal survey. Perit Dial Int 2:S445-S449

25. Honda M, Iitaka K, Kawaguchi H, Hoshii S, Akashi S, Kohsaka T, Tuzuki K, Yamaoka K, Yoshiwaka N, Karashima S, Itoh Y, Hatae K (1996) The Japanese national registry data on pediatric CAPD patients: a ten year experience. A report of the study group of pediatric PD conference. Perit Dial Int 16:269-275

26. Schaefer F, Kandert M, Feneberg R (2002) Methodological issues in assessing peritonitis incidence in children. Perit Dial Int 22:234-238

27. Ramalakshmi S, Bernardini J, Piraino B (2003) Nightly intermittent peritoneal dialysis to initiate peritoneal dialysis. Adv Perit Dial 19:111-114

28. Vas S, Oreopoulos DG (2001) Infections in patients undergoing peritoneal dialysis. Infect Dis Clin North Am 15:743-774

29. Zelenitsky S, Barns L, Findlay I, Alfa M, Ariano R, Fine A, Harding G (2000) Analysis of microbiological trends in peritoneal dialysis-related peritonitis from 1991 to 1998. Am J Kidney Dis 36:1009-1013

30. Piraino B, Bernardin J, Florio T, Fried L (2003) Staphylococcus aureus prophylaxis and trends in Gram-negative infections in peritoneal dialysis patients. Perit Dial Int 23:456-459

31. Mujais S (2006) Microbiology and outcomes of peritonitis in North America. Kidney Int Suppl 103:S55-S62

32. MacGinley R, Cooney K, Alexander G, Cohen S, Goldsmith JA (2002) Relapsing culture-negative peritonitis in peritoneal dialysis patients exposed to icodextrin solution. Am J Kidney Dis 40:1030-1035

33. Boer WH, Vos PF, Fieren MW (2003) Culture-negative peritonitis associated with the use of icodextrin containing dialysate in twelve patients treated with peritoneal dialysis. Perit Dial Int 23:33-38

34. Toure F, Lavaud S, Mohajer M, Lavaud F, Canivet E, Nguyen P, Chanard J, Rieu P (2004) Icodextrin-induced peritonitis: study of five cases and comparison with bacterial peritonitis. Kidney Int 65:654-660

35. Martis L, Patel M, Giertych J, Mongoven J, Taminne M, Perrier MA, Mendoza O, Goud N, Costigan A, Denjoy N, Verger C, Owen WF Jr (2005) Aseptic peritonitis due to peptidoglycan contamination of pharmacopoeia standard dialysis solution. Lancet 365:588-594

36. Vychytil A, Remon C, Michel C, Wiliams P, Rodriguez-Carmona A, Marron B, Vonesh E, van der Heyden S, Filho JC (on behalf of the Extraneal Peritonitis Study Group) (2008) Icodextrin does not impact infectious and culture-negative peritonitis rates in peritoneal dialysis patients: a 2-year multicenter, comparative, prospective cohort study. Nephrol Dial Transplant 23:3711-3719

37. Goldie SJ, Kiernan-Troidle L, Torres C, Gorban-Brennan N, Dunne D, Kliger AS, Finkelstein FO (1996) Fungal peritonitis in a large chronic peritoneal dialysis population: A report of 55 episodes. Am J Kidney Dis 28:86-91

38. Wang AYM, Yu AWY, Li PKT, Lam PKW, Leung CB, Lai KN, Lui SF (2000) Factors predicating outcome of fungal peritonitis in peritoneal dialysis: Analysis of a 9-year experience of fungal peritonitis in a single center. Am J Kidney Dis $36: 1183-1192$ 
39. Warady BA, Bashir M, Donaldson LA (2000) Fungal peritonitis in children receiving peritoneal dialysis: a report of the NAPRTCS. Kidney Int 58:384-389

40. Lui SL, Lo CY, Choy BY, Chan TM, Lo WK, Cheng IK (1996) Optimal treatment and long-term outcome of tuberculous peritonitis complicating continuous ambulatory peritoneal dialysis. Am J Kidney Dis 28:747-751

41. Piraino B (2000) Peritoneal infections. Adv Ren Replace Ther 7:280-288

42. Troidle L, Kilger AS, Gorban-Brennan N, Fikrig M, Golden M, Finkelstein FO (1996) Nine episodes of CPD-associated peritonitis with vancomycin-resistant enterococci. Kidney Int 50:1368-1372

43. Von Baum H, Schehl J, Geiss HK, Schaefer F (1999) Prevalence of vancomycin-resistant enterococci among children with endstage renal failure. Clin Infect Dis 29:912-916

44. Holtta TM, Ronnholm KA, Holmberg C (1998) Influence of age, time, and peritonitis on peritoneal transport kinetics in children. Perit Dial Int 18:590-597

45. Andreoli SP, Leiser J, Warady BA, Schlichting L, Brewer ED, Watkins SL (1999) Adverse effect of peritonitis on peritoneal membrane function in children on dialysis. Pediatr Nephrol 13:1-6

46. Warady BA, Fivush B, Andreoli SP, Kohaut E, Salusky I, Schlichting L, Pu K, Watkins S (1999) Longitudinal evaluation of transport kinetics in children receiving peritoneal dialysis. Pediatr Nephrol 13:571-576

47. Aflaiw A, Vas S, Oreopoulos DG (1999) Peritonitis in patients on automated peritoneal dialysis. Contrib Nephrol 129:213-228

48. Schaefer F (2003) Management of peritonitis in children receiving chronic peritoneal dialysis. Paediatr Drugs 5:315-325

49. Warchol S, Roszkowska-Blaim M, Sieniawska M (1998) Swan neck presternal peritoneal dialysis catheter: Five-year experience in children. Perit Dial Int 18:183-187

50. Chadha V, Jones LL, Ramirez ZD, Warady BA (2000) Chest wall peritoneal dialysis catheter placement in infants with a colostomy. Adv Perit Dial 16:318-320

51. Warady BA, Hebert D, Sullivan EK, Alexander SR, Tejani A (1997) Renal transplantation, chronic dialysis, and chronic renal insufficiency in children and adolescents. The 1995 annual report of the North American pediatric renal transplant cooperative study. Pediatr Nephrol 11:49-64

52. Furth SL, Donaldson LA, Sullivan EK, Watkins SL, North American Pediatric Renal Transplant Cooperative Study (2000) Peritoneal dialysis catheter infections and peritonitis in children: A report of the North American Pediatric Renal Transplant Cooperative Study. Pediatr Nephrol 15:179-182

53. Twardowski ZJ, Dobbie JW, Moore HL, Nichols WK, DeSpain JD, Anderson PC, Khanna R, Nolph KD, Loy TS (1991) Morphology of peritoneal dialysis catheter tunnel: macroscopy and light microscopy. Perit Dial Int 11:237-251

54. Eklund B, Honkanen E, Kyllonen L, Salmela K, Kala AR (1997) Peritoneal dialysis access: prospective randomized comparison of single-cuff and double-cuff straight Tenckhoff catheters. Nephrol Dial Transplant 12:2664-2666

55. Strippoli GF, Tong A, Johnson D, Schena FP, Craig JC (2004) Catheter type, placement and insertion techniques for preventing peritonitis in peritoneal dialysis patients. Cochrane Database Syst Rev (4):CD004680

56. Crabtree JH, Burchette RJ (2006) Prospective comparison of downward and lateral peritoneal dialysis catheter tunnel-tract and exit-site directions. Perit Dial Int 26:677-683

57. Smith CA (1997) Reduced incidence of peritonitis by utilizing "flush before fill" in APD. Adv Perit Dial 13:224-226

58. Warady BA, Ellis EN, Fivush BA, Kum GM, Alexander SR, Brewer ED, Ogrinc F, Watkins S (2003) Flush before fill in children receiving automated peritoneal dialysis. Perit Dial Int 23:493-498
59. Verrina E, Honda M, Warady BA, Piraino B (2000) Prevention of peritonitis in children on peritoneal dialysis. Perit Dial Int 20:625-630

60. Gadallah MF, Ramdeen G, Mignone J, Patel D, Mitchell L, Tatro S (2000) Role of preoperative antibiotic prophylaxis in preventing postoperative peritonitis in newly placed peritoneal dialysis catheters. Am J Kidney Dis 36:1014-1019

61. Strippoli GF, Tong A, Johnson D, Schena FP, Craig JC (2004) Antimicrobial agents for preventing peritonitis in peritoneal dialysis patients. Cochrane Database Syst Rev (4):CD004679

62. Bonifati C, Pansini F, Torres DD, Navaneethan SD, Craig JC, Strippoli GF (2006) Antimicrobial agents and catheter-related interventions to prevent peritonitis in peritoneal dialysis: Using evidence in the context of clinical practice. Int $\mathbf{J}$ Artif Organs 29:41-49

63. Sardegna KM, Beck AM, Strife CF (1998) Evaluation of perioperative antibiotics at the time of dialysis catheter placement. Pediatr Nephrol 12:149-152

64. Katyal A, Mahale A, Khanna R (2002) Antibiotic prophylaxis before peritoneal dialysis catheter insertion. Adv Perit Dial 18:112-115

65. Piraino B (1996) Management of catheter-related infections. Am J Kidney Dis 27:754-758

66. Piraino B (1997) Infectious complications of peritoneal dialysis. Perit Dial Int 17:S15-S18

67. Piraino B (1998) Peritonitis as a complication of peritoneal dialysis. J Am Soc Nephrol 9:1956-1964

68. Szeto CC, Chow KM, Leung CB, Wong TYH, Wu AKL, Wang AYM, Lui SF, Li PKT (2001) Clinical course of peritonitis due to Pseudomonas species complicating peritoneal dialysis: A review of 104 cases. Kidney Int 59:2309-2315

69. Twardowski ZJ, Prowant BF (1997) Current approach to exit-site infections in patients on peritoneal dialysis. Nephrol Dial Transplant 12:1284-1295

70. Auron A, Simon S, Andrews W, Jones L, Johnson S, Musharaf G, Warady BA (2007) Prevention of peritonitis in children receiving peritoneal dialysis. Pediatr Nephrol 22:578-585

71. Luzar MA, Coles GA, Faller B, Slingeneyer A, Dah GD, Briat C, Wone C, Knefati Y, Kessier M, Peluso F (1990) Staphylococcus aureus nasal carriage and infection in patients on continuous ambulatory peritoneal dialysis. $\mathrm{N}$ Engl J Med 322:505-559

72. Piraino B, Perlmutter JA, Holley JL, Bernardini J (1993) Staphylococcus aureus peritonitis is associated with Staphylococcus aureus nasal carriage in peritoneal dialysis patients. Perit Dial Int 13:S332-S334

73. Blowey DL, Warady BA, McFarland KS (1994) The treatment of Staphylococcus aureus nasal carriage in pediatric peritoneal dialysis patients. Adv Perit Dial 10:297-299

74. Kingwatanakul P, Warady BA (1997) Staphylococcus aureus nasal carriage in children receiving long-term peritoneal dialysis. Adv Perit Dial 13:281-284

75. Oh J, von Baum H, Klaus G, Schaefer F, European Pediatric Peritoneal Dialysis Study Group (EPPS) (2000) Nasal carriage of Staphylococcus aureus in families if children on peritoneal dialysis. Adv Perit Dial 16:324-327

76. Bernardini J, Piraino B, Holley J, Johnston JR, Lutes R (1996) A randomized trial of Staphylococcus aureus prophylaxis in peritoneal dialysis patients: mupirocin calcium ointment $2 \%$ applied to the exit-site versus cyclic oral rifampin. Am J Kidney Dis 27:695700

77. The Mupirocin Study Group (1998) Nasal mupirocin prevents Staphylococcus aureus exit-site infection during peritoneal dialysis. J Am Soc Nephrol 11:2403-2408

78. Miller MA, Dascal A, Portnoy J, Mendelson J (1996) Development of mupirocin resistance among methicillin-resistant Staphy- 
lococcus aureus after widespread use of nasal mupirocin ointment. Concise Commun 17:811

79. Thomas DG, Wilson JM, Day MJ, Russell AD (1999) Mupirocin resistance in staphylococci: Development and transfer of isoleucyl-tRNA systhetase-mediated resistance in vitro. J Appl Microbiol 86:715-722

80. Annigeri R, Conly J, Vas S, Dedier H, Praskashan KP, Bargman JM, Jassal V, Oreopoulos D (2001) Emergence of mupirocinresistant Staphylococcus aureus in chronic peritoneal dialysis patients using mupirocin prophylaxis to prevent exit-sire infection. Perit Dial Int 21:554-559

81. Bernardini J, Bender F, Florio T, Sloand J, Palmmontalbano L, Fried L, Piraino B (2005) Randomized, double-blind trial of antibiotic exit site cream for prevention of exit site infection in peritoneal dialysis patients. J Am Soc Nephrol 16:539-545

82. Holloway M, Mujais S, Kandert M, Warady BA (2001) Pediatric peritoneal dialysis training: characteristics and impact on peritonitis rates. Perit Dial Int 21:401-404

83. Zaruba K, Peters J, Jungbluth H (1991) Successful prophylaxis for fungal peritonitis in patients on continuous ambulatory peritoneal dialysis: six years' experience. Am J Kidney Dis 17:43-46

84. Robitaille P, Merouani A, Clermont MJ, Hebert E (1995) Successful antifungal prophylaxis in chronic peritoneal dialysis: a pediatric experience. Perit Dial Int 15:77-79

85. Lo WK, Chan CY, Cheng SW, Poon JF, Chan DT, Cheng IK (1996) A prospective randomized control study of oral nystatin prophylaxis for candida peritonitis complicating continuous ambulatory peritoneal dialysis. Am J Kidney Dis 28:549-552

86. Thodis E, Vas SI, Bargman JM, Singhal M, Chu M, Oreopoulos DG (1998) Nystatin prophylaxis: its inability to prevent fungal peritonitis in patients on continuous ambulatory peritoneal dialysis. Perit Dial Int 18:583-589

87. Williams PF, Moncrieff N, Marriott J (2000) No benefit in using nystatin prophylaxis against fungal peritonitis in peritoneal dialysis patients. Perit Dial Int 20:352-353

88. Prasad KN, Prasad N, Gupta A, Sharma RK, Verma AK, Ayyagari A (2004) Fungal peritonitis in patients on continuous ambulatory peritoneal dialysis: a single centre Indian experience. J Infect 48:96-101

89. Schaefer F, Klaus G, Mueller-Wiefel DE, Mehls O, MidEuropean Pediatric Peritoneal Dialysis Study Group (MEPPS) (1999) Intermittent versus continuous intraperitoneal glycopeptide/ ceftazidime treatment in children with peritoneal dialysis-associated peritonitis. J Am Soc Nephrol 10:136-145

90. Boyce NW, Wood C, Thomson NM, Kerr P, Atkins RC (1988) Intraperitoneal (IP) vancomycin therapy for CAPD peritonitis a prospective, randomized comparison of intermittent $\mathrm{v}$ continuous therapy. Am J Kidney Dis 12:304-306

91. Low CL, Bailie GR, Evans A, Eisle G, Venezia RA (1996) Pharmacokinetics of once-daily IP gentamicin in CAPD patients. Perit Dial Int 16:379-384

92. Low CL, Gopalakrishna K, Lye WC (2000) Pharmacokinetics of once daily intraperitoneal cefazolin in continuous ambulatory peritoneal dialysis patients. J Am Soc Nephrol 11:1117-1121

93. Blowey DL, Warady BA, Abdel-Rahman S, Frye RF, Manley HJ (2007) Vancomycin disposition following intraperitoneal administration in children receiving peritoneal dialysis. Perit Dial Int 27:79-85

94. Jorres A, Topley N, Witowski J (1993) Impact of peritoneal dialysis solutions on peritoneal immune defense. Perit Dial Int 13:S291-S294

95. Cameron JS (1995) Host defences in continuous ambulatory peritoneal dialysis and the genesis of peritonitis. Pediatr Nephrol 9:647-662

96. de Boer AW, Levi M, Reddingius RE, Willems JL, van den Bosch S, Schroder CH, Monnens LA (1999) Intraperitoneal hypercoagu- lation and hypofibrinolysis is present in childhood peritonitis. Pediatr Nephrol 13:284-287

97. Bouts AHM, Davin J-C, Krediet RT, van der Weel MB, Schroder $\mathrm{CH}$, Monnens L, Nauta J, Out TA (2000) Immunoglobulins in chronic renal failure of childhood: effects of dialysis modalities. Kidney Int 58:629-637

98. Neu AM, Furth SL, Lederman HM, Warady BA, Fivush B (1998) Hypogammaglobulinemia in infants on peritoneal dialysis. Perit Dial Int 18:440-443

99. Flanigan MJ, Lim VS (1991) Initial treatment of dialysis associated peritonitis: A controlled trial of vancomycin versus cefazolin. Perit Dial Int 11:31-37

100. Milliken SP, Matzke GR, Keane WF (1991) Antimicrobial treatment of peritonitis associated with continuous ambulatory peritoneal dialysis. Perit Dial Int 11:252-260

101. Mueller-Wiefel DE (1999) Treatment of peritonitis in pediatric continuous peritoneal dialysis. Perit Dial Int 19:S450-S457

102. Hospital Infection Control Practices Advisory Committee (HICPAC) (1995) Recommendations for preventing the spread of vancomycin resistance. Infect Control Hosp Epidemiol $16: 105-113$

103. Smith TL, Pearson ML, Wilcox KR, Cruz C, Lancaster MV, Robinson-Dunn B, Tenover FC, Zervos MJ, Band JD, White E, Jarvis WR (1999) Emergence of vancomycin resistance in Staphylococcus aureus. N Engl J Med 316:927-931

104. Sieradzki K, Roberts RB, Haber SW, Tomasz A (1999) The development of vancomycin resistance in a patient with methicillin-resistant Staphylococcus aureus infection. N Engl J Med 340:517-523

105. Warady BA, Reed L, Murphy G, Kastetter S, Karlsen E, Alon U, Hellerstein S (1993) Aminoglycoside ototoxicity in pediatric patients receiving long-term peritoneal dialysis. Pediatr Nephrol 7:178-181

106. Shemin D, Maaz D, St Pierre D, Kahn SI, Chazan JA (1999) Effect of aminoglycoside use on residual renal function in peritoneal dialysis patients. Am J Kidney Dis 31:14-20

107. Singhal MK, Bhaskaran S, Vidgen E, Bargman JM, Vas SI, Oreopoulos DG (2000) Rate of decline of residual renal function in patients on continuous peritoneal dialysis and factors affecting it. Perit Dial Int 20:429-438

108. Chadha V, Blowey DL, Warady BA (2001) Is Growth a valid outcome measure of dialysis in children on peritoneal dialysis? Perit Dial Int 21:S179-S184

109. Boeschoten EW, Ter Wee PM, Divinho J (2006) Peritoneal dialysis-related infections recommendations 2005-an important tool for quality improvement. Nephrol Dial Transplant 21:Sii31Sii33

110. Baker RJ, Senior H, Clemenger M, Brown EA (2003) Empirical aminoglycosides for peritonitis do not affect residual renal function. Am J Kidney Dis 41:670-675

111. Grady R (2003) Safety profile of quinolone antibiotics in the pediatric population. Pediatr Infect Dis J 22:1128-1132

112. Noel GJ, Bradley JS, Kauffman RE, Duffy CM, Gerbino PG, Arguedas A, Bagchi P, Balis DA, Blumer JL (2007) Comparative safety profile of levofloxacin in 2523 children with a focus on four specific musculoskeletal disorders. Pediatr Infect Dis 26:879-891

113. Gokal R, Alexander SR, Ash S, Chen TW, Danielson A, Holmes C, Joffe P, Moncrief J, Nichols K, Piraino B, Prowant B, Slingeneyer A, Stegmayr B, Twardowski Z, Vas S (1998) Peritoneal catheters and exit site practices. Toward optimum peritoneal access: 1998 update. Pediatr Dial Int 18:11-13

114. Vychytil A, Lorenz M, Schneider B, Horl WH, Haag-Weber M (1998) New criteria for management of catheter infections in peritoneal dialysis patients using ultrasonography. J Am Soc Nephrol 9:290-296 
115. Fried L, Piraino B (2000) Peritonitis. In: Gokal R, Khanna R, Krediet R, Nolph K (eds) Textbook of peritoneal dialysis. Kluwer, Norwell, pp 545-564

116. Blowey DL, Garg UC, Kearns GL, Warady BA (1998) Peritoneal penetration of amphotericin B lipid complex and fluconazole in a pediatric patient with fungal peritonitis. Adv Perit Dial 14:247-250

117. Dahl NV, Foote EF, Searson KM, Fein JL, Kapoian T, Steward CA, Sherman RA (2000) Pharmacokinetics of intraperitoneal fluconazole during continuous cycling peritoneal dialysis. Ann Pharmacother 32:1284-1289

118. Klaus G, Schaer F, Querfeld U, Soergel M, Wolf S, Mehls O (1992) Treatment of relapsing peritonitis in pediatric patients on peritoneal dialysis. Adv Perit Dial 8:302-305

119. Plum J, Sudkamp S, Grabensee B (1994) Results of ultrasoundassociated diagnosis of tunnel infections in continuous ambulatory peritoneal dialysis. Am J Kidney Dis 23:99-104

120. Majkowski NL, Mendley SR (1997) Simultaneous removal and replacement of infected peritoneal dialysis catheters. Am J Kidney Dis 29:706-711

121. Posthuma N, Borgstein PJ, Eijsbouts Q, ter Wee PM (1998) Simultaneous peritoneal dialysis catheter insertion and removal in catheter-related infections without interruption of peritoneal dialysis. Nephrol Dial Transplant 13:700-703

122. Lui SL, Li FK, Lo CY, Lo WK (2000) Simultaneous removal and reinsertion of Tenckhoff cathetersfor treatment of refractory exit-site infection. Adv Perit Dial 16:195-197
123. Lui SL, Yip T, Tse KC, Lam MF, Lai KN, Lo WK (2005) Treatment of refractory Pseudomonas aeruginosa exit-site infection by simultaneous removal and reinsertion of peritoneal dialysis catheter. Perit Dial Int 25:560-563

124. Swartz RD, Messana JM (1999) Simultaneous catheter removal and replacement in peritoneal dialysis infections: update and current recommendations. Adv Perit Dial 15:205208

125. Warady BA, Schaefer FS (2004) Peritonitis. In: Warady BA, Schaefer FS, Fine RN, Alexander SR (eds) Pediatric dialysis. Kluwer, Dordrecht, pp 393-414

126. Honda M, Warady B (2008) Long-term peritoneal dialysis and encapsulating peritoneal sclerosis in children. Pediatr Nephrol doi:10.1007/s00467-008-0982-Z

127. Maruyama Y, Nakayama M (2008) Encapsulating peritoneal sclerosis in Japan. Perit Dial Int 28:S201-S204

\section{Answers:}

1. Correct answer: B

2. Correct answer: $\mathrm{E}$

3. Correct answer: D

4. Correct answer: A

5. Correct answer: $\mathrm{C}$ 